\title{
Apuntes sobre el autor y el protagonista de una cantiga «d'escarnho e de mal dizer»
}

\author{
Manuel López Fernández ${ }^{1}$
}

A la memoria del profesor, maestro y señor, que para mi fue don José Luis Martín.

\section{RESUMEN}

El paso de Pelay Pérez Correa por la encomienda de Alcácer do Sal, antes de alcanzar el cargo de comendador de Uclés, es poco conocida en España. Aqui se le nombra más a partir de 1241 cuando es designado comendador mayor de Castilla y luego maestre de la Orden de Santiago. Sin embargo, su etapa de comendador en Portugal es digna de tener en cuenta si consideramos la documentación que ha llegado hasta nosotros y más si la contrastamos con la opinión que de él nos ofrece el trovador portugués Pero Mendes da Fonseca en una cantiga de escarnio.

\section{PALABRAS CLAVE}

Orden de Santiago, Encomienda de Uclés, Pelay Pérez Correa. Poesia gallegoportuguesa, Pero Mendes da Fonseca.

\section{ABSTRACT}

The stage of Pelay Pérez Correa in the commandery of Alcacer, before he reached the position of commander of Uclés, is not well known in Spain. In our country, he is better known after his nomination as commander in chief of Castile in 1241 and later, when he was appointed master of the Order of Santiago. However, his stage as commander of Portugal is worth to mention if we take into consideration the documentation available today. Even more if we check these documents with the opinion about him of the portuguese troubadour Pero Mendes da Fonseca in a scoffing poem.

KEYWORDS:

Order of Santiago, Commandery of Uclés, Pelay Pérez Correa, Galician-Portuguese poetry, Pero Mendes da Fonseca.

' UNED. Centro Asociado de Algeciras. 


\section{A MODO DE PRÓLOGO}

Existe una cantiga de escarnio en el Cancionero de la Biblioteca Nacional de Lisboa (CBN. 1600), y también en el Cancionero de la Biblioteca Vaticana (CV. 1132), en la que el trovador portugués Pero Mendes da Fonseca trata de reflejar la personalidad y trayectoria de un personaje al que llama "Paio de maas artes..." y que, por lo que más tarde veremos, no puede ser otro que el maestre santiaguista Pelay Pérez Correa; sobre este hombre, citado como maestre de Uclés en las crónicas medievales aragonesas, castellanas y portuguesas - dicho por orden alfabético - elaboramos no hace mucho un trabajo que constituyó nuestra tesis doctoral en la que fuimos dirigidos precisamente por el profesor José Luis Martín. Después de lo que antecede, posiblemente intuyan los lectores que este artículo no aparece aquí por pura casualidad; y está en lo cierto el que así piense puesto que la inclusión del mismo en este número de "Espacio Tiempo y Forma" ha sido consecuencia de unos hechos relativamente cercanos y pretendo corresponder ahora, aunque sea a título póstumo, a un gesto del director de nuestra tesis. Porque se dio la circunstancia de que no hace mucho tiempo el profesor José Luis Martín nos envió un artículo de Elisa María Ferreira ${ }^{2}$ sobre una cantiga titulada "Chegou Paio de maas artes" y acompañaba a las fotocopias del trabajo una breve nota manuscrita en la que nos indicaba que lo había encontrado entre sus papeles y lo enviaba porque «... creo que puede resultarte de más utilidad que a mi"..

Y es que ni de la existencia de la citada cantiga ni del contenido de ella - a la que habiamos tenido acceso en Portugal ${ }^{3}$ después de encuadernados los textos de la tesis para entregar a los miembros del tribunal que habían de juzgarla-, se habló en la defensa de la tesis a pesar de nuestra insistencia en hacerlo porque considerábamos a título personal que la composición era poco conocida en España y, por otro lado, venía a confirmar nuestra postura de que Pelay Pérez Correa no habia ocupado encomienda alguna en Portugal antes de serle concedida la de Alcácer do Sal. Don José Luis estuvo de acuerdo en nuestra apreciación, pero se negó en redondo a sacar a relucir el tema y nos aconsejó que preparáramos otro trabajo sobre el asunto porque "una investigación histórica no termina nunca y no es justo hablar de algo que no ha sido presentado a los miembros del tribunal's. Sobran los comentarios a estas palabras y posiblemente resulte innecesario señalar que el gesto de enviarme el trabajo de Elisa María Ferreira indicaba a las claras que no se había olvidado de cuanto acabo de relatar.

Expuesto lo anterior, y lamentando que este trabajo vea la luz por circunstancias luctuosas, hemos tratado de aportar algunos datos sobre el autor de la cantiga y del personaje principal de la misma debiendo anticipar al respecto que el tema

${ }^{2}$ El artículo en cuestión apareció en Cuadernos de Estudios Gallegos. Santiago de Compostela, (1978-1980). Tomo XXXI, pp. 361-369.

${ }^{3}$ En el mes de febrero de 2002, gracias a la intormación que nos proporcionó el profesor Luis Filipe de Oliveira, de la Universidad del Algarve. 
no se agota aquí dado lo ambiguo del sentido profundo de la cantiga y lo complejo que resulta encontrar datos sobre estos hombres del siglo xIII.

\title{
LA CANTIGA, SU AUTOR Y LA OPINIÓN SOBRE "PAIO»
}

Sin más demoras, lo que procede en estos momentos es dar a conocer la composición de Pero Mendes y para ello transcribimos íntegramente el texto de la misma siguiendo la edición crítica de Manuel Rodrigues Lapa ${ }^{4}$.

\author{
Chegou Paio de maas arte \\ con seu cerame de Chartes; \\ e non leeu el nas partes \\ que chegase a uu mes, \\ e do lues ao martes \\ foi comendador d'Ocrés. \\ [E] semelha-me busnardo, \\ viind 'en seu ceramen pardo; \\ e, u non ouvesse reguardo \\ en ne un dos dez e tres, \\ log' ouve mant' e tabardo \\ e foi comendador d'Ocrés \\ E chegou per ua strada \\ descalço, gran madurgada, \\ u se non catavan nada \\ duu om' atan rafez: \\ cobrou manto con espada \\ e foi comendador d'Ocrés
}

Estamos pues ante una sátira en la que el poeta ridiculiza a un personaje burlándose de su apariencia externa y escaso intelecto, justificando su rápido ascenso dentro de la Orden de Santiago gracias a sus malas artes, aspecto éste que coloca en un primer plano hasta el punto que la cantiga es conocida por su primer verso, "Chegou Paio de maas artes". Sin lugar a dudas que éste es un detalle frecuente en las cantigas de escarnio y sin lugar a dudas, también, que el autor nos está hablado de un freire de la Orden de Santiago por dos detalles bien simples: el primero, e importantísimo para el autor a juzgar por su reiteración, es que se hace mención a la encomienda de Uclés; el otro viene reflejado en la segunda estrofa cuando se hace alusión a los "dez e tres", o sea, a los Trece, órgano de gobierno interno y exclusivo de la Orden de Santiago que, como es bien sabido, estaba compuesto por los trece comendadores más importantes de la Orden entre los que figuraban los comendadores mayores de los diferentes reinos hispánicos. Ahora bien, si se está hablando de un freire santiaguista llamado "Paio», coetáneo del autor a tenor de lo que éste nos dice, y que después de pasar por el reino de Portugal alcanzó el cargo de comendador de Uclés, llegamos a la conclusión que

4 Rodrigues LAPA, Manuel: Cantigas d'escarnho e de mal dizer dos cancioneiros medievais galegoportugueses. Editorial Galaxia. Vigo, 1965, p. $589, n .^{\circ} 399$ de la colección. 
el freire en cuestión tiene que ser el comendador portugués Paio Peres Correia dado que la suma de tales circunstancias no concurren en ningún otro comendador de Uclés. De modo que lo relatado en la cantiga de escarnio que aquí traemos a colación debió ocurrir antes de noviembre de 1241, fecha en la que el comendador de Alcácer do Sal tue elegido comendador de Uclés en un Capítulo General que la Orden celebró en León.

Y como a tenor de lo que se nos dice en la cantiga el autor parece haber vivido en primera persona los hechos que relata — sólo nos hace sospechar de tal circunstancia cuando dice "e non leu el nas partes"-, podemos suponer que ambos eran contemporáneos. Quién era entonces este trovador medieval que firma Pero Meendez da Fonseca, y qué motivos tenía para ridiculizar al ya comendador de Uclés, señal inequívoca de que la cantiga fue escrita después de 1241. Desde luego, el profesor Rodrigues Lapa no aporta dato alguno sobre la personalidad del autor de la cantiga. Sin embargo, Elisa Maria Ferreira es más generosa en detalles y, de entrada, nos dice que Pero Mendes es un poeta mal conocido dentro de la poesía gallego-portuguesa y que sólo se conocen de él unas cuantas cantigas de amor y una sola de «mal-dizer», a la que precisamente hace objeto de su estudio. Por ello se ve impelida a buscar más datos sobre el trovador y localiza a dos individuos que, con este nombre y viviendo en los años centrales del siglo xIII, pudieron ser autores de la misma ${ }^{5}$. El primero de ellos fue un prelado que murió en 1270 y el otro parece ser una persona que vivía todavía en 1289 , pero más ligada al mundo poético si se atiene a las referencias de ciertos autores portugueses ${ }^{6}$. Sin embargo, como ninguno de los dos personajes parece reunir las garantías suficientes como para asignarles la paternidad de la cantiga, Elisa Maria Ferreira plantea tres hipótesis sobre la persona de Pero Mendes y en la primera de ellas apunta a que debió ser alguien que tuvo un roce con Pelay Pérez Correa entre 1241 y 1275, año este último en que murió el maestre santiaguista. Y más adelante llega a la conclusión que sea quien sea el autor de la composición poética, éste no parece dominar la técnica con soltura pues sus cantigas de amor son bastantes anodinas y la que hace contra «Paio» no resulta nada ingeniosa; intuye, por tanto, que Pero Mendes pueda ser un "poeta de circunstancias" que se ha metido a trovador por «pura necesidad de descargar su bilis».

Cualquiera que lea las estrofas precedentes pensará que no van descaminadas las apreciaciones de Elisa María Ferreira porque la cantiga rezuma mala intención en toda su extensión, nos transmite la sensación de que "Paio» es un pobretón escaso de entendederas y, además, desprotegido de sus superiores. Lo de pobretón lo decimos porque el "cerame" al que se hace alusión en la primera estrofa no era otra cosa que una simple capa, duradera y relativamente barata de paño de Char-

Para más detalles véase la obra ya citada de Ferreira Priegue, Elisa Maria: “Chegou Paio de maas artes".... pp. 366-367

Según dice la autora de la nota anterior, José Joaquim Nunes recoge en su obra "Cantigas de Amor" un apunte en el que se le relaciona con un documento de compraventa citado en Monarchia Lusitana, $\mathrm{V}$. 
tres que servía a los humildes jornaleros y quedaba muy por debajo del tabardo señorial?. No hay dudas de que "Paio" era considerado como un pobre para el autor y esto debía quedar bastante claro para la gente de la época; pero si lo anterior no fuese suficiente vuelve a recalcarlo - para ellos y para nosotros - cuando dice que "Paio" llegó "descalço" a Portugal hasta el punto que hubo de entrar casi a escondidas como temeroso y avergonzado de ser visto. $Y$ si lo anterior es un descrédito para "Paio", no lo será menos cuando se le tache de idiota ya que el término "busnardo", según nos aclara el profesor Rodrigues Lapa, tiene este significado en francés y provenzal arcaico ${ }^{8}$. No conforme el autor con lanzar este cultismo para sus coetáneos, acentúa la estupidez de «Paio" unos versos más abajo cuando emplea otra expresión más al uso de los portugueses de aquellos tiempos; la palabra utilizada en esta ocasión es "rafez»y, como bien se sabe, este concepto viene a significar escaso, que vale poco. Sin embargo, este hombre pobre y oscuro que llega sin contar con el apoyo de sus superiores jerárquicos, los "dez e tres", no tarda en encumbrarse alcanzando "manto con espada" y por añadidura llega a ser comendador de Uclés que, como hemos dicho, era por entonces la encomienda mayor de la Orden en el reino de Castilla. Tan importante era la encomienda de Uclés en aquellos tiempos, que la Orden de Santiago era conocida en los distintos reinos peninsulares como la Orden de Uclés.

Sin lugar a dudas, este último logro de "Paio" era lo más llamativo para Pero Mendes da Fonseca pues al convertirlo en el estribillo de la cantiga lo repite hasta tres veces. Artificio poético o envidia manifiesta, el autor quiere llamar la atención sobre el rápido encumbramiento de un hombre de clase humilde en el seno de la Orden de Santiago. Se podía pensar que alcanzar la encomienda de Uclés era el objetivo vital de nuestro trovador y ve que, de la noche a la mañana, el sueño se le escapa de las manos en favor de un hombre que él consideraba inferior en muchos sentidos. Si nos tomamos la cantiga al pie de la letra, resulta de claridad meridiana que Pero Mendes no veía a Paio Peres Correia con buenos ojos y por eso lo ridiculiza una y otra vez hasta el punto de desacreditarlo. Pero como la trayectoria de este último personaje está más o menos clara para nosotros y no coincidimos en opinar igual que Pero Mendes da Fonseca, para clarificar la verdadera intención de la cantiga nos sentimos obligados a buscar más datos sobre este personaje. La búsqueda la iniciamos en el "Livro de Linhagens do conde D. Pedro» y, precisamente en estas listas genealógicas, encontramos un hombre así llamado que era hijo de un segundo matrimonio de Meen Gonçalves da Fonseca y padre, a su vez, de un freire de la Orden de Santiago llamado Gonzalo Peres ${ }^{9}$.

Seguimos a MiChaelis de VAsconcelos, Carolina: Revisia Lusitana III. Lisboa, 1895, p. 142. Esta autora comenta aqui los versos 1-2, y 7-8 de la cantiga en cuestión y dice al respecto que la misma habla de un pobretón que de repente y sin merecerlo fue nombrado comendador de Uclés, cambiando "o seu cerame grisalho de panno de Chartes" por un rico manto y la espada de caballero.

* Rodrigues LAPA: Cantigas d'escarnho..., p. 589.

Véase asi en la edición crítica que José Matosso hace del "Livro de linhagens do conde D. Pedro". Portugaliae Monumenta Histórica. Lisboa, 1980. capitulo 66E - 1 y 2 . Según nos dice el editor en la introducción de la obra, el autor de la misma debió ser Don Pedro de Barcelos entre los años 1340 y 1344. 
A tenor de esta cita, no debe sorprendernos que la historiadora portuguesa Leontina Ventura ${ }^{10}$ considere a este Gonzalo Peres como al personaje que figura siendo comendador de Palmela en 1235, cuando Paio Peres Correia comendador de Alcácer concede Fuero a Vilanova de Canha ". La historiadora que aqui seguimos dice que Gonzalo Peres Magro da Fonseca era hijo de Pero Mendes da Fonseca, nieto de Meem Gonçalves da Fonseca y bisnieto de Gonzalo Viegas Magro, lo que significa que por línea paterna era descendiente de Egas Moniz -el mayordomo mayor del rey Alfonso Enrique de Portugal-. Si esto fuese así la animadversión que el trovador siente hacia "Paio" estaría llena de sentido; lo estaría porque Pero Mendes descendia de un linaje de renombre y, si su hijo era el comendador de Palmela, tal vez soñara con la posibilidad de que este vástago suyo alcanzara la encomienda de Alcácer cuando Paio Peres Correia llegó de Castilla para ocupar tal cargo.

Sin embargo, no es ésta la opinión de todos los genealogistas portugueses ya que Figueiras Gayo nos dice en su “Nobiliario» que Mem Gonçalves da Fonseca -el padre del trovador Pero Mendes- no era hijo de Gonzalo Viegas Magro, sino de Gonzalo Paes da Fonseca ${ }^{12}$. Pero además de esta discrepancia en la línea ascendente de Pero Mendes, el profesor Sotto Mayor Pizarro ${ }^{13}$ viene a puntualizar ciertos detalles con respecto a la línea descendente de nuestro trovador y demuestra que los santiaguistas Gonzalo Peres Magro y Gonzalo Peres da Fonseca no eran la misma persona, aunque los dos fueron freires de la Orden de Santiago. Para el historiador que ahora seguimos el freire de la la familia "Magro" era hijo de Pero Veigas Magro y descendía por línea bastarda de Egas Moniz, en tanto que el santiaguista de la familia "Fonseca" si era realmente hijo de Pero Mendes y éste a su vez de Mem Gonçalves da Fonseca. Como este hombre todavía vivia en 1258 según se confirma por la lectura de las Inquiriçoes del rey Alfonso III de Portugal ${ }^{14}$, y como de este año es la última referencia documental que tenemos de Gonzalo Peres Magro ${ }^{15}$ - del que ya dijimos que era comendador de Palmela en 1235-, llegamos a la conclusión que el santiaguista de la familia «Magro» era de la misma generación que el abuelo del freire Gonzalo Peres da Fonseca. Por tanto, no sería extraño que nuestro trovador fuese el "Pero Mendes" que Elisa María Ferreira encontraba documentado en 1289 porque en una fecha posterior, concretamente en 1294, todavía lo encuentra Antonio Rosende de Oliveira. Según este último autor, el trovador Pero Mendes da Fonseca casó con una sobrina del canciller de Alfon-

ro VentuRa, Leontina: A nobreza da Corte de Afonso III. Facultade de Letras. Universidade de Coimbra. Coimbra, 1992, vol. II, pp. 747-748.

1 Arquivo Nacional da Torre do Tombo (ANTT). Livro dos Copos, folio CCXLr.

12 FIgueIras Gayo: Nobiliario de familias portuguesas. Braga, 1939, tomo XIV, pp. 166-167.

13 Sotro MAYOR PIZARRo, José Augusto: Linhagens medievais portuguesas. Genealogias e estratégias (1279-1325). Universidade Moderna do Porto. Porto, 1999, vol. I, pp. 480 y 504-505.

${ }_{14}$ Esta es una de las referencias que nos ha proporcionado nuestro amigo el profesor Luis Filipe de Oliveira en la correspondencia que hemos tenido sobre el asunto, la cual nos ha servido de referencia y guia en todo momento. Por ello queremos hacer público nuestro más sincero agradecimiento.

15 La última referencia documental que tenemos de Gonzalo Perez Magro es de julio de 1258. Puede verse en ANTT. Chancelaria de Afonso III. Livro I fol. XXVII. 
so IIl de Portugal, Estevao Anes, y se relacionó también con el hijo del mayordomo real, Joao Peres de Aboim ${ }^{16}$.

Asi que Pero Mendes da Fonseca ya estaba bien situado en la corte, y no exclusivamente por sus virtudes como trovador, en los últimos años del reinado de Alfonso III; por tanto, nuestro poeta debia ser un niño de corta edad, si es que había nacido antes ${ }^{17}$, cuando Paio Peres Correia llegó a Portugal en 1232 para hacerse cargo de la encomienda de Alcácer do Sal. Por ello hemos de suponer que la información que nos proporciona en la cantiga no puede ser de primera mano y por consiguiente creemos que para justificarse ante sus coetáneos tiene que echar mano de un "e non leeu el nas partes", muestra evidente que él no podía tener certeza con respecto al tiempo exacto que Paio Peres Correia había estado al frente de la encomienda de Alcáçer. Punto éste que ampliaremos a continuación.

\section{EL COMENDADOR DE ALCÁCER EN LA DOCUMENTACION.}

No hará falta insistir en el hecho sobradamente conocido de que el Pelay Pérez Correa de la documentación castellana es la misma persona que el Paio Peres Correia de la portuguesa. Este hombre, como ya recogiera Francisco de Rades y Andrada ${ }^{18}$ en su día y con antelación el conde Pedro de Barcelos en su "Livro de linhagens", ela portugués de nacimiento. La familia Correa tenía su solar en Farelaes ${ }^{19}$ según se dice en el "Nobiliario del conde de Barcelos" ${ }^{20}$ y sus padres fueron Pedro Paes Correa y Dordea Peres de Aguiar. Si nos atenemos a las indicaciones de José Mattoso ${ }^{21}$, son los Correa una familia nobiliaria pero no próxima a la corte y lo mismo opina al respecto el profesor Sotto Mayor Pizarro ${ }^{22}$, quien viene a calificarla como nobleza "intermedia» con una expresión "marcadamente local». De acuerdo con ambos autores, ninguno de sus miembros parece que desempeñara algún cargo palatino de importancia con anterioridad al maestre de Santiago.

16 Resende de Olivelra, Antonio: Depois do espectáculo trovadoresco. A estructura dos cancioneiros peninsulares e as recolas dos séculos xil e xiv. Lisboa, 1994, pp. 421-422.

17 Recordemos que era hijo de un segundo matrimonio de Mem Gonçalves da Fonseca.

18 Rades y Andrada, Francisco: Crónica de las tres ordenes y caballerias, de Santiago. Calatrava y Alcantara. Facsimil de ediciones El Albir. Barcelona, 1980, pg. 31.

19 El lugar está a once kilómetros al sureste de Barcelos y a unos dieciocho al suroeste de Braga. Véase Soares de Azevedo Barbosa de Pinho Leal. Augusto: Portugal Antigo e Moderno. Lisboa, 1875, volumen III, pg. 226. y volumen IV, pg. 457. También puede verse en la Grande Enciclopedia Portuguesa e Brasileira, bajo las voces "Barcelos" y "Monte de Farelaes". Debo y agradezco el conocimiento de estos puntuales datos a Fernando Mario Correia da Silva

20 Nobiliario deí conde de Barcelos. Traducido al castellano por Manuel de Faria y Sousa. Madrid, 1646. Esta edición incluye abundantes notas criticas de Juan Bautista de Lavaña, del marqués de Montalbo y de Alvaro Ferreyra de Vera. Ninguno de los críticos contradice al autor de la obra en lo que respecta a los datos que aporta sobre los Correa

${ }_{21}$ Matroso, José: Historia de Portugal. A Monarquía Feudal (1096-1480). Dirección de José Mattoso. Editorial Estampa. Lisboa, 1993, pgs. 178-182.

22 Sotto Mayor Pizarro: Linhanges medievais...., vol. 2, p. 390. 
A decir verdad, nada sabemos del ingreso de Pelay Pérez Correa en la Orden de Santiago. La primera referencia documental que de él tenemos es de agosto de 1228 cuando asiste como testigo a un acuerdo entre doña Aurembiaix, condesa de Urgel, y el maestre santiaguista Pedro González ${ }^{23}$ descartando por inexacta ${ }^{24}$ la cita de Rades cuando habla de un "Pelay Pérez comendador de Portugal" en el año 1222. Puede que el futuro maestre de Santiago no hubiese entrado todavía en la Orden, porque no conocemos su fecha de ingreso en la misma, pero sí nos inclinamos a creer que cuando lo hizo fue de la mano de algún familiar dado que tal situación era algo corriente en Portugal por aquellas fechas ${ }^{25}$. No sería extraño, a tenor de lo que venimos diciendo, que de la mano de ese desconocido padrino llegara hasta las proximidades del entonces comendador de Alcácer, Fernando Peres Chacín, que poco después fue nombrado maestre de la Orden. Es probable que de esta manera llegara a formar parte de los freires que constituían el séquito del maestre en un puesto secundario, pero junto al maestre. Lo suponemos asi porque no podemos explicarnos de otra manera que, cuando el nuevo maestre santiaguista Pedro González acompaña a la condesa de Urgel hasta Lérida, el freire "Pelay Correa" figure entre los confirmantes de un acuerdo entre la condesa y la Orden. Para nosotros existe después un vacio documental con respecto al entonces freire portugués, a pesar de buscar en la documentación santiaguista siguiendo los pasos del maestre Pedro González por el reino de León entre los años 1229 a $1231^{26}$.

Sin embargo, cuando el maestre llega a Castilla celebra en Uclés un nuevo Capítulo General y precisamente en el mismo aparece «Pelay Correya comendador de Portugal» en el documento en que la Orden entrega a Ordoño Álvarez la encomienda manchega de Villanueva de la Fuente, en marzo de 1232, según podemos ver en el Tumbo Menor de Castilla ${ }^{27}$. Hasta ahora todo parece lógico si ex-

AHN. OO. MM. Uclés, 207/13. Publicado en Bullarium de Santiago, pg. 90. También en SÁNZ DE LA Maza: La Orden... doc. n. 12, pg. 244. Aunque en la primera publicación se transcribe "Pelai" y en la segunda "Pelayo", la realidad es que en el documento se dice "Pelay".

24 Rades Y ANDRAda: Chronica ..., folio 26v. En esta referencia el autor cita a un comendador de Portugal que, además, era trece de la Orden. Al consultar el documento en cuestión encontramos que figura un "Pelagius Petri", pero el cargo de comendador de Portugal que añade Rades no consta en dicho documento. Tal vez resulte interesante decir que el asi citado se trata de un caballero leonés.

25 Véase al respecto la opinión de José Mattoso en "Ricos-homens, infançoes e cavaleiros. A nobreza medieval portuguesa nos séculos xI e xi". Guimaraes \& C ${ }^{3}$. Editores. Lisboa, 1982, p. 227. Según nos dice aqui este autor, era frecuente el parentesco entre freires de las órdenes militares y además aprecia un mecanismo en el sistema por el cual supone que la entrada de un miembro de alguna familia en una orden militar aseguraba, casi siempre, el ingreso de otro miembro de la generación siguiente.

26 Sabemos que Pedro González estuvo en Cataluña hasta el otoño de 1228. Después salio hacia el reino de León y en la primavera de 1229 convocó Capitulo General de la Orden en San Marcos de León. A consecuencia de las circunstancias militares que se dieron en el reino de León, el maestre no lo abandonó hasta la primavera de 1231. En estos años los santiaguistas intervinieron en las conquistas de Cáceres, Montánchez, Mérida y Badajoz. Los confirmantes de la Orden que aparecen en los documentos del Maestre son comendadores y no simples freires. No obstante, tenemos la sospecha que si el freire Pelay Correa pertenecia al séquito del maestre Pedro González, muy bien pudo intervenir en los hechos militares que se vivieron en torno a las mencionadas plazas antes de ser nombrado comendador de Alcácer.

AHN. Códice 1046-B. Libro III/31, pgs. 273-274. 
ceptuamos las clásicas lagunas documentales que para nosotros existen, pero surge en estas fechas un hecho discordante si contrastamos la documentación castellana y portuguesa; hecho que posiblemente nos de la primera pista sobre los motivos por los cuales Pelay Pérez Correa pudo ser mal visto por algunos naturales del reino de Portugal. Siguiendo a Mario Raúl de Sousa ${ }^{28}$, vemos que por aquellas fechas era Mem Alvares quien desempeñaba todavía el cargo de comendador de aquel reino; y de las posibles situaciones que podían explicar tales circunstancias, nos inclinamos a creer que Pelay Pérez Correa perteneciera a la Casa del maestre Pedro González y éste dispusiera su nombramiento al frente de la encomienda de Alcácer por alguna razón que desconocemos, pero que de entrada nos obliga a preguntarnos ¿por qué no fue Mem Alvares al Capítulo General de Uclés?

La pregunta anterior es difícil de responder para nosotros, pero si esto ocurrió asi -que Pelay Pérez Correa alcanzara el cargo de comendador de Portugal por designación directa del maestre Pedro González y sin haber ocupado otra encomienda con anterioridad-, nada de sorprendente tendría que nuestro hombre no fuese bien recibido en este reino por el resto de los comendadores y llegara a la corte portuguesa, para presentar sus credenciales ${ }^{29}$, con cierta timidez y austeridad $^{30}$ hasta el punto de parecer un idiota a más de uno de los que presenciaron el acto y entre los que posiblemente estuviera Mem Gonçalves da Fonseca, el padre del trovador Pero Mendes. Pero de aquí a que Pelay Pérez fuese un hombre de escaso intelecto dista un mundo porque hasta para emplear "malas artes" y no caer en el enredo hace falta un cierto grado de inteligencia y las repercusiones posteriores a tal nombramiento así lo demuestran. Para adentrarse en este aspecto, quizá sea conveniente seguir la opinión de Sousa Cunha quien conoce y ha estudiado la documentación portuguesa de la Orden con más profundidad que nosotros; viene a decir este autor al respecto que para febrero de 1235 , fecha en que Pelay Pérez Correa concede fuero a Vilanova de Canha, los santiaguistas disponian ya de un potencial humano y económico que contrasta con los que disponían tres años antes. Y dice esto el historiador portugués porque en este espacio de tiempo se había doblado el número de encomiendas de la Orden en el reino de Portugal ${ }^{31}$ y ninguno de los hombres situados al frente de las mismas eran ya los mismos que en 1232 .

28 Sousa Cunha, Mario Raúl: A Orden Militar de Santiago (das origens a 1327). Universidade do Porto. Tesis policopiada, pg. 47. Nos dice este autor que el 29 de marzo de 1232 la Orden entregó a Pedro Fernandes de Sande ciertas propiedades y en el documento figura Mem Alvares como el personaje que encabezaba a los santiaguistas en Portugal.

29 No queremos dejar de indicar aqui que los comendadores mayores de un reino eran los representantes políticos de su maestre ante el monarca de cualquier reino.

30 Con respecto al modo de vestir de los santiaguistas véase Echaniz Sans, Maria: Austeridad versus lujo. El vestuario y los freires de la Orden de Santiago. Anuario de Estudios Medievales. N. ${ }^{\circ} 23$. Barcelona, 1993.

31 Sousa Cunha: A Ordem...,pg. 47 y 69-70. Junito a la encomienda de Alcácer, en 1232 los santiaguistas tenian: Santos, Arruda, Palmela y Almada. En 1235, además de las anteriores encomiendas, aparecen Santarém, Setúbal, Cabrela, Vilanova de Canha y Montemor o Novo. 
Con estos «homens novos", por emplear los mismos términos que el historiador que aquí seguimos, parece ser que el nuevo comendador de Portugal había emprendido una empresa que pronto trajo sus frutos ya que el 31 de marzo de 1235 la Orden recibió del monarca portugués, Sancho II, el castillo de Aljustrel con unos términos extensísimos. El documento, escrito en latín, viene a decir después de la invocación inicial: «Las acciones de los hombres desaparecen muchas veces de su memoria si no se registraran en escritos. Por eso yo, Sancho II, por la gracia de Dios rey de Portugal e hijo del ilustre rey Alfonso y de la reina doña Urraca y nieto de los ilustrísimos reyes Sancho de Portugal y Alfonso de Castilla, por mi voluntad y acuerdo de mi corte, hago este documento de donación y perpetua seguridad a la Orden de Santiago y a vos, Pelay Pérez ${ }^{32}$ comendador de Alcácer....»

Aunque la donación fue en marzo de 1235, hay que suponer que para entonces Aljustrel ya estuviese en poder de la Corona portuguesa, así que lo más probable es que la conquista de esta fortaleza se hubiera realizado en la campaña del año anterior ${ }^{33}$ y que los santiaguistas pudieran quedar como fronteros del rey; porque Aljustrel - que domina el curso alto de un afluente del Sado- era una de las llaves del curso de este último río que como bien sabemos desemboca por Alcácer do Sal, base de partida de los freires de la Orden en sus incursiones hacia tierras de musulmanes. Dadas estas circunstancias, estratégicas y geográficas, nos atrevemos a suponer que no fue esta de 1234 la primera intervención de los espatarios ${ }^{34}$ después que Pelay Pérez Correa fuera nombrado comendador mayor de Portugal. Y lo creemos así porque en los flancos de esta vía de penetración que resultaba el Valle del Sado existian otras importantes villas que debieron asegurarse con anterioridad, caso de Alvito, del que quizá sea interesante apuntar que la Crónica da Conquista do Algarve dice que fue ganada por don Pelay ${ }^{35}$.

Sea como fuere, el caso es que a partir de esa fecha los espatarios siguieron interviniendo por su cuenta o en colaboración con otras fuerzas porque, el 19 de enero de 1236, el rey de Portugal hace donación a la Orden, y al comendador de Alcácer, del castillo y villa de Sesimbra ${ }^{36}$. No hay duda que para estas incursiones sobre tierras de musulmanes los espatarios se apoyaban en su castillo de Aljustrel porque el emplazamiento de éste en tierras del Alentejo venía a ser como un trampolín hacia las tierras de los islamitas, circunstancia que no debieron desaprovechar los santiaguistas portugueses y la muestra de ello es que, el 4 de noviembre de 1237, Sancho II cedía a la Orden los derechos de patronazgo que tenía

32 Como nos podemos imaginar, el documento dice "Pelagius Petri"

3. El Capitulo General de 1234 se celebró en Montánchez en el mes de mayo. Parece ser que Pelay Pérez no asistió a la asamblea si nos atenemos a lo que se dice en AHN. OO. MM. Uclés 308/9: “...todos los XIII que eran en Cabildo de Montanches, tambien de Leon como de Castiella...". Nada se dice del unico trece portugués por aquellas fechas.

${ }^{34}$ Asi se conocia a los freires santiaguistas en Portugal.

35 Crónica de Cinco Reis de Portugal. Inédito cuatrocentista reproducido do Códice 886 da Biblioteca Pública Municipal do Porto. Ediçao de Artur de Magalhaes Basto. Vol. I. Livraria Civiliçao. Porto, 1945, p. 203.

${ }^{36}$ AHN. OO. MM. Uclés, $263 / 4$ y ANTT. Livro dos Mestrados, folio CLXXIr. 
en las iglesias de las villas de Alcácer, Palmela y Almada ${ }^{37}$. Exactamente no sabemos que posesiones se iban incorporando a la Corona de Portugal, pero debemos suponer que estas concesiones reales en tierras situadas en la retaguardia no se deberían únicamente a la generosidad de Sancho II; algo debian poner de su parte los espatarios y la muestra de ello es que existen referencias documentales para pensar que fueron ellos los que se apoderaron de Mértola ${ }^{38}$ en la campaña de 1238, razón por la que el 16 de enero de 1239 el comendador de Alcácer recibe el mismo día- los castillos de Mértola y Alfaiar de la Peña ${ }^{39}$.

Situados ya en el Valle del Guadiana, las huestes portuguesas no tardaron en poner sitio a Ayamonte en el verano del último año citado. Sancho Il intervino en estas operaciones que supusieron la introducción de una cuña entre los musulmanes de ambas márgenes del citado rio ${ }^{40}$ y debió encargar el mantenimiento de la misma al comendador de Alcácer. Era la prueba irrefutable de que los santiaguistas habían intervenido en el cerco y que el monarca confiaba en la Orden de Santiago, muestra de ello es que para agradecer sus servicios y apoyarle en la misión encomendada le concedió el mismo día, 2 de mayo de 1240, las fortalezas y términos de Ayamonte y Cacela ${ }^{41}$. Con ello, en sólo ocho años, la Orden de Santiago había más que doblado la extensión de sus posesiones en el reino de Portugal y además era la única institución que guardaba todas las fronteras terrestres del Algarve, con todo lo que ello significaba en aquellos tiempos. El siguiente paso para los espatarios fue hacerse con Tavira y posiblemente ya la tuvieran bajo su control cuando en 1241 Pelay Pérez Correa dejó la encomienda de Alcácer y fue trasladado a Castilla haciéndose cargo de la encomienda mayor de este reino; esto es, fue designado comendador de Uclés después de permanecer al frente de la Orden en Portugal más de nueve años con los resultados que acabamos de exponer.

\section{CONCLUSIONES}

Después de conocer que "Paio de maas artes" no alcanzó la encomienda de Uclés "do lues ao marte" y que el autor de la cantiga no pudo vivir directamente la llegada del nuevo comendador de Portugal en 1232, habrá que preguntarse una vez más por los motivos que llevaron a Pero Mendes a tomar como objeto de su escarnio la persona del maestre de la Orden de Santiago y, precisamente, en su

37 AHN. OO. MM. Uclés, 263/5 y ANTT. Livro dos Copos, folio XCIXr.

38 Véase AHN. OO. MM. 263/ 11 Se dice aquí: "...fostes uos e uossos yrmaos con nossa Orden quando fillaron Mertola a mouros...". De haberla ganado el rey Sancho II suponemos que se hubiera citado tal circunstancia de alguna manera.

39 AHN. OO. MM. Uciés, 263/6 y 263/7. ANTT. Livro dos Copos, folios LXXXVIIIV y CLIIr. (La primera referencia de cada Archivo para Mértola y la segunda para Alfaiar).

40 Brandao, frei Antonio: Crónicas de D. Sancho II e D. Afonso III. Edición e introdución de A. Magalhaes Basto. Livraria Civiliçao. Porto, 1946, p. 68.

${ }^{41}$ AHN. OO. MM. Uclés, 263/7 y ANTT. Livro dos Copos, folio CLIIIr y Livro dos Mestados, folio $C L X X X V I r$. Esta última referencia es válida sólo para Cacela pues no hemos encontrado referencias a dicha donación en España. 
etapa como comendador de Alcáçer. La respuesta o respuestas precisas nos son desconocidas por ahora, aunque de entrada no debemos descartar la escasa simpatía del trovador hacia el maestre de Santiago. Pero como debemos conjugar la intencionalidad de sus estrofas con la verdad histórica, llegamos a la conclusión que no debemos tomarnos la cantiga al "pie de la letra" y que todo el juego semántico que en ella se despliega no es otra cosa que eso, un juego donde el poeta pone de manifiesto su ingenio para denunciar un asunto social muy de actualidad en aquella época y recogido en más de una cantiga de escarnio ${ }^{42}$; el asunto no era otro que el rápido ascenso social de algunos caballeros entre los que, indiscutiblemente, pudieron encontrarse algunos miembros de las órdenes militares.

Pero tenemos la impresión que para cuando Pero Mendes escribió la cantiga que ahora nos incumbe, hacia tiempo que había pasado la época de las rápidas promociones sociales a base de enfrentarse a los musulmanes porque tales enfrentamientos habian terminado prácticamente desde los primeros años del reinado de Alfonso III; o sea, desde el momento mismo en que este rey colocó el Algarve bajo el control de la Corona portuguesa en 1250. Por tanto, parece razonable pensar que Pero Mendes tenía perdidas las esperanzas de que su hijo ganara prestigio y honra en una rápida carrera militar - por eso carece de ataduras para censurar el asunto- cuando él se movía entre importantes personajes de la corte a los que no les podía resultar grato la llegada de ciertos intrusos a los que no debían considerar mejor que a simples competidores de las prebendas propias de los puestos de gobierno. Parece lógico pensar que esta nobleza antigua y acomodada no mirara bien a los advenedizos, llegaran por el camino que llegaran, y trataban de mofarse de ellos siempre que podían ridiculizándolos en sus momentos de esparcimiento a base de distorsiones grotescas. No puede haber dudas, después de lo que hemos expuesto, que el caso de Pelay Pérez Correa era paradigmático en aquellos años y tal vez recordara el trovador Pero Mendes algún comentario jocoso de sus mayores sobre el modo y manera en que el Correa llegó a la corte portuguesa. La anécdota no necesitaría más que ciertos retoques burlescos para alcanzar la ridiculización total del personaje y provocar la risa ${ }^{43}$ entre sus contertulios.

${ }^{42}$ LaIn, Milagro: La poesia profana de Alfonso X. Revista de Occidente, n. ${ }^{\circ} 43$. Madrid, 1984, pp.145-165.

${ }^{43}$ Según la autora de la nota anterior, el juego y la risa son las claves para interpretar la poesía profana de aquellos tiempos. 